УДК $1: 3$

$10.17213 / 2075-2067-2020-6-254-263$

\title{
ДЕТЕРМИНАНТЫ И САМОДЕТЕРМИНАНТЫ ОБЩЕСТВЕННОЙ ЖИЗНИ В РОССИЙСКОМ ОБЩЕСТВЕ
}

\author{
(C) 2020 г. М. Л. Крольман , Е. С. Косарева ${ }^{* *}$, С. А. Дементьев \\ "Ростовский государственный экономический университет (РИНХ), \\ 2. Ростов-на-Дону, Россия \\ ** Ростовский юридический институт МВД России, г. Ростов-на-Дону, Россия \\ **** Южно-Российский гуманитарный институт, г. Ростов-на-Дону, Россия
}

Целью статьи является социально-философская рефлексия детерминат и самодерминат общественной жизни в российском обществе на основе социально-философской саморефлексии.

Методология исследования. В работе предлагается «неомарксистский» вариант социального детерминизма, в котором общественное сознание является практическим, складывается из отношений, которые поддерживает сочиальный класс с другими группами.

Результаты исследования. Введение в исследовательский дискурс и детерминант, и самодетерминант общественной жизни согласно позиции автора означает сохранение традиции социального детерминизма, несмотря на деконструктивизм социального постмодерна. Сложность исследовательской ситуации состоит в том, что в концептуальном самодвижении требуется выработать позицию взаимообусловленности, взаимозаивисимости общественной жсизни на основе определения детерминант как объективированных результатов деятельности людей, а самодетерминант - как субъектного выбора моделей сочиального действия в рамках возможностей, трактуемых, как детерминанты общественной жизни. Авторы приходят к выводу, что на современном этапе в российском обществе отмечается возникновение новых связей и отношений как следствие информаичионной и индивидной революиии в общественной жизни.

Перспективы исследования. Важным выводом можно считать введение в соииально-философский дискурс детерминант и самодетерминант общественной жизни, и этот концепт может быть использован в дальнейших социально-философских исследованиях.

Ключевые слова: общественная жизнь; детерминанты и самодетерминанты; российское общество; совместная деятельность; модели сочииального действия.

\section{DETERMINANTS AND SELF-DETERMINANTS OF PUBLIC LIFE IN RUSSIAN SOCIETY}

\author{
(C) 2020 M. L. Krolman*, E.S. Kosareva**, S. A. Dementiev ${ }^{* * *}$ \\ "Rostov State University of Economics (RSUE), Rostov-on-Don, Russia \\ ${ }^{* *}$ Rostov Law Institute of the Ministry of Internal Affairs of Russia, Rostov-on-Don, Russia \\ ${ }^{* * *}$ South Russian Humanitarian Institute, Rostov-on-Don, Russia
}

The purpose of the article is a socio-philosophical reflection of the determinants and selfdeterminates of social life in Russian society based on socio-philosophical self-reflection. 
Research methodology. The paper suggests a «neo-marxist» version of social determinism, in which social consciousness is practical and consists of the relations that a social class maintains with other groups.

Research result. Introduction to the research discourse of both determinants and selfdeterminants of social life according to the author's position means preserving the tradition of social determinism, despite the deconstructivism of social postmodernism. Research the complexity of the situation is that in the concept-movement is required to develop a position of interdependence, of vzaimozavisimost public life based on the definition of the determinant of the objectified results of human activity, and semideterminate - as the subject-choice models of social action within the possibilities that are treated as determinants of social life. The authors come to the conclusion that at the present stage in Russian society there is the emergence of new ties and relations, as a consequence of the information and individual revolution in public life.

Prospects of the study. An important conclusion can be considered the introduction of determinants and self-determinants of social life into the socio-philosophical discourse, and this concept can be used in further socio-philosophical research.

Key words: social life; determinants and self-determinants; Russian society; joint activity; models of social action.

Актуальность. Российский социальный исследователь Ж. Т. Тощенко характеризует оценку состояния и тенденций общественной жизни в российском обществе как парадоксальную [10]. Согласно его позиции «разговор о парадоксе» обрел социальнопрактическое звучание, так как наблюдаемые абберации массового сознания сложно свести только к субъективному фактору. Реально мы являемся свидетелями социальной текучести и социальной турбулентности в рамках общественной жизни. Здесь нельзя ограничиться образными высказываниями: феномен общественной жизни многослоен, и под ним содержится противоречивость оценок и прогнозов, связанных с выбором теоретико-методологических подходов исследования. Но проблема состоит не только и не столько в этом. Общественная жизнь в российском обществе «парадоксальна», парадоксальность проявляется в поведении людей в социальных практиках, но, рассматривая конкретные формы парадоксов, нельзя надеяться на то, что найдена ключевая формула социально-философской рефлексии общественного развития. Например, относясь критически к ленинской формулировке общественного сознания как отражения общественного бытия, мы попадаем в достаточно противоречивую ситуацию «неожиданности при анализе общественной жизни». Призыв разобраться с теоретико-методологическими основами парадоксальности в социальных феноменах является верным, но не содержит однозначных критериев оценки аналитической, объяснительной и прогностической способностей конкретных концептуальных схем.

Стало модным утверждать, что мы живем в эпоху позднего модерна или постмодерна, и общественная жизнь является «анахронизмом» социального модерна, что в контексте индивидуализации, атомизации, эксклюзии, расцвета «тусовочности» невозможно заявлять претензии на исследование общественного сознания по универсальным теоретическим принципам. Постмодерн «исчез» из поля теоретического интереса, перестал быть концепцией «парадигмального характера», но реально социальная мысль вынуждена признать, что мы живем в эпоху конца больших повествований, и цели социально-гуманитарного знания ограничиваются пределами теоретического допущения и ограничения.

В этом смысловом контексте общественная жизнь может восприниматься «сборочно», быть агрегатом разнонаправленных противоречивых явлений и выполнять роль рамочной схемы. Другими словами, для исследователя важным становится не позитив- 
ное, претендующее на полноту понятия, а негативное, определяющее то, что не относится к сфере общественной жизни как социальной повседневности.

Таким образом, получается, что социально-гуманитарная мысль отстает от реальностей общественной жизни, и определенные в постмодерне понятия «нарративности», «смысловой неразрешимости», «релевантности» не могут служить ориентиром для исследования общественной жизни в российском обществе, содержат скептицизм, приводящий к социальной агностике, но соответственно постулируют гетерогенность, неоднородность общественного сознания и общественного поведения в качестве подступа к решению исследовательских проблем. По своей сути, постмодернизм является «провоцирующим», так как создает ситуации фрагментации общественной жизни, конструирует предпосылки отказа от исследования детерминант и самодетерминант его развития.

Это означало бы уход от научности и объективности, от языка, фиксирующего константы общественной жизни, и ставило бы под сомнение полезность социально-гуманитарного знания в качестве не только «интеллектуальной игры», но и формы социального самопознания. Социально-философская мысль пережила кризис самоопределения, так как в условиях ухода от марксистской детерминистской концепции признания принципов многомерности и междисциплинарности привели к «невыносимости» множества определений. Попытки выработать более или менее внятную социальную эпистемологию через признание типов контекстуализма сделали ясным, что социально-философская рефлексия ставит другие вопросы, связанные с различением философской проблематизации и социально-практических контекстов [8].

Иначе говоря, общественная жизнь является предметом социально-философской рефлексии при допущении его рассмотрения концептульно, на основе принятия теоретического выбора и уверенности в том, что исследование обладает прогностикой, является типологизацией по схеме инвариантности социальных событий и фактов. Общественная жизнь в российском обществе действительно может показаться гибридной, аморфной и па- радоксальной, но, не имея принципиальных возражений против использования данных понятий, нужно принять за исходное детерминанты общественной жизни как определение взаимообусловленности явлений социальной жизни.

Актуально применительно к общественной жизни подчеркнуть установку на разграничения социоприродных и социальных процессов на понимание недопустимости естественнонаучных проекций и осознание методологической трудности, возникающей из классификации объективных и субъективных факторов общественной жизни. Понимание общественной жизни в качестве продукта деятельности людей делает возможным рефлексию социокультурных реальностей, которая проявляется и в восприятии социальной действительности, и в выборе конкретных социальных стратегий.

Методология. Из вышесказанного ясно: признавая обоснованность «недостаточности» объективизма и понимания того факта, что в современном мире не действуют правила «железных законов», ясно также и то, что социально-философская мысль не является конструктивной и плодотворной, если становится жертвой концептуального произвола. Следует подчеркнуть: уязвимость постмодернизма и состоит в том, что предлагается отказаться от концептуализации общественного сознания.

Не претендуя на теоретический ревайвализм, связанный с возвратом к социальному детерминизму, мы не можем не сформулировать ситуацию следующим образом: раскрыв механизмы социально-философской детерминации, немецкий мыслитель К. Маркс подверг критике иллюзорно-сверхисторическую позицию [5]. Обоснование неприемленности создания социально метафизических схем означало поиск социально-философских универсальностей, работающих в реальном измерении общественного сознания. Существенно новым было понимание социальнофилософских проблем не как проблем чисто философского сознания, а проблем практического смысла, связанного с социальной жизнедеятельностью людей.

Но здесь следует отметить, что марксистский подход упустил поворот к субъ- 
ективизму: позиция философского радикализма, критика и ниспровержение иных социально-философских теорий привели марксизм к состоянию «тупикового одиночества» и превращения со временем в мертвую идеологическую схему. Интеллектуальная и культурная история Европы, как пишет $\Phi$. Тернер, в этом отношении сохраняла традицию отражать внешнюю реальность [9], поэтому необходимо принять исходным поворот к субъективизму, к тому, что общественная жизнь является продуктом общественного опыта, чувственных впечатлений, и при согласии с И. Кантом о роли человеческого разума в организации общественного сознания возникает возможность обрести уверенность в социальном самопознании, реализации субъективной свободы в концептуальном выборе.

Однако, это не означает, что общественное сознание «конструируется» спонтанно, что детерминанты общественного сознания есть только дань сциентизму. Восприятие общественного сознания требует личной свободы исследователя, нахождения вне влияния неоспоримых законов и осознания социальной предопределенности. Так как общественное сознание - это результат социальной деятельности, основанной на взаимообусловленности социальных явлений, логически последовательным шагом можно считать компоиментарность детерминант и самодетерминант общественного сознания.

В российской социально-философской теории до сих пор схематично конкурирует объективистский и субъективистский (социально-конструктивистский) подходы, и, не ориентируясь на сравнительный культурно-исторический анализ, нужно принимать такое деление как условное.

Позиции объективистов не совпадают полностью с отстаиванием марксистского детерминизма, а включают принятие других детерминант общественного сознания внеэкономического характера (фактор этатизма, исторического наследия, геополитической специфики). С другой стороны, субъективистов нельзя безоговорочно относить к конструктивизму. Для исследователей обоих направлений свойственно стремление занять позицию «золотой середины», рассматривать общественное сознание с учетов обоих фак- торов, но при этом делать акцент на доминанту детерминизма или самодетерминизма.

Эта ситуация определяется осознанием ограниченности одностороннего универсализма, влиянием поворота к субъективизму, принятием неклассической философской методологии. Относительно марксистского детерминизма исследователи Э. Бальбар и И. Валерстайн писали «о Марксе за пределами Маркса» [2]. Признавая двусмысленность положения о зависимости общественного сознания от экономики, ученые делали акцент на характере социально-трудовых отношений, на исследовании институтов собственности и политической жизни. Результатом является «перманентная диалектика» практик и мыслей.

Таким образом, предлагается «неомарксистский» вариант социального детерминизма. В нем общественное сознание является практическим, складывается из отношений, которые поддерживает социальный класс с другими группами, но не в качестве обособленного внутриинституциональной системы, а социального субъекта, позиционирующего собственные социальные интересы и установки и через них воспринимающего общественные явления. Общественное сознание является конструктом социального позиционирования и социального восприятия. Такой подход позволяет отказаться от сверхдетерминированной диалектики и становится конструктом социальной деятельности.

В российской социально-философской мысли идеи Э. Балибара и Э. Валерстайна не получили развития, так как, вероятно, сложилась ситуация теоретической нетерпимости, в которой трудно было отстоять позицию уверенности и избежать обвинения в ревизионизме. Общественное сознание «идеологизировалось», внимание стало уделяться, с одной стороны, у объективистов схемам исторической непреложности, цивилизационной специфики России, с другой - опологии философского либерализма, в которой детерминанты общественного сознания рассматривались сверхкритически, как фантомы, возрождающие традицию сверхчувственного общественного бытия.

Результаты исследования. В постсоветской школе критического марксизма основной 
является мысль о том, что о структуре социума аргументируется известное ранее положение о периодизации общественного развития более сложное, чем сталинская «пятичленка» [3]. Важным является акцент на исследование противоречий пределов и объективно возможных путей снятия капитализма как «царства экономической необходимости». Выражая отношение к объективированным закономерностям как внешнему проявлению социальности, критические марксисты определяют свою исследовательскую задачу в качестве гуманизации общественной жизни, утверждая, что марксизм не является учением о железных закономерностях и за ним есть будущее, в котором аутентичное рассмотрение марксизма содержит последствием путь в свободу человека.

Таким образом, критический марксизм, пытаясь сохранить гуманистический преобразовательный пафос в учении, характеризует объективные закономерности как свободу личности в познании общественной необходимости. Другими словами, марксистская теория описывается как сохраняющая эвристический и объяснительный потенциал в познании детерминант общественного развития, которые являются объективными, так как определяются совокупностью социальных факторов и условий, создаваемых коллективным человеком, обществом.

Это положение можно рассматривать как воспроизводство традиций детерминизма, с той поправкой, что детерминизм общественного развития является результатом сознательной жизни людей. Самодетерминанты общественной жизни проявляются в следующем: из вариаций объективных условий индивиды выбирают то, что они могут присвоить и актуализировать. По такой классификации к самодетерминантам общественной жизни и общественного сознания относятся социальное позиционирование индивидов и определяемый осознанием своих позиций, оценкой жизненных шансов выбор индивидов. В результате доминирующими являются объективные закономерности, так как, повторяя известную мысль Маркса, критические марксисты говорят, что индивид не волен распоряжаться как угодно, а действует в условиях сложившихся социальных обстоятельств.
Обновленность марксистских позиций в провозглашенном подходе заключается в том, что российское общество, представляя сложную систему взаимосвязанных параметров, развивается по логике детерминант и самодетерминант, и можно говорить о переменности тенденций развития в зависимости от того, выступают ли на первое место объективные закономерности детерминанты или общественное развитие испытывает влияние самодетерминант, субъективного фактора, автономности от внешних обстоятельств.

Представленная трактовка социального развития российского общества позволяет сделать некоторые выводы о том, что в нынешнем российском обществе не действуют детерминанты рынка как господствующей системы. В большей степени работает конструкция нерыночных механизмов, сращенности власти и бизнеса, где не проявляется в чистом виде схема рыночных отношений, а детерминирующим фактором можно считать результаты властного (политического) влияния.

Трактовка российского общества как гибридного, переходного, связана с тем, что определяется неоднозначность детерминант, их проявление в специфическом виде, не имеющем нормативного аналога. Определить детерминанты общественной жизни и общественного сознания можно только учитывая парадоксальное противоречивое переплетение социальных обстоятельств. В общей форме ответ сводится к следующему: естественное развитие экономики до уровня онаучивания приводит к исключению вариантов жесткого детерминизма, социального фатализма, ставит преграду волевым (волентаристским) политическим решениям. Можно говорить о том, что критический марксизм, пытаясь доказать, что марксизм является единственно верной схемой развития российского общества, так как основывается на социальном познании экономики и занятого в ней индивида, содержит мощный потенциал познания и преобразования, поскольку избегает индетерминизма и, как следствие, погружение общества в социальный хаос.

Здесь уместно отметить, что критические марксисты признают теоретические трудности, связанные с переинтерпретацией марксистского наследия применительно к России. Повторяя известное положение о том, 
что советский социализм был результатом бюрократизации системы, абберации общественного сознания, которая представлялась эпифеноменом общественного бытия, авторы призывают рассматривать процесс возрастания духовного производства как самодетерминанты общественной жизни и общественного сознания. Согласно этому положению, которое подтверждается научно-технической и информационной революциями, можно говорить о новом детерминизме, «овердетерминизме», когда общественная жизнь и общественное сознание «неразделимы», проявляются как целостность общественного развития. Общественная жизнь становится сознательной, онаученной, в то время как общественное сознание содержит импульсы к практическому преобразованию общественной жизни в контексте интеллектуализации экономической деятельности, интеллектуального капитала индивида.

Ясно, что критические марксисты исходят из концепции желаемого будущего российского общества, из признания детерминизма как социальной разумности, проявляемой и в логике развития экономики, и во взглядах и настроениях людей. Естественно, что характеризует критический марксизм - это замыкание пределов социально-философской рефлексии в экономике и политике, где они основываются на пересмотрении известных положений марксизма о классах, диктатуре пролетариата, экономических отношениях. Детерминанты и самодетерминанты общественной жизни и общественного сознания описываются как факторы вне сферы социальной повседневности. Таким образом, утверждается, что российское общество нуждается в обновленном марксизме.

В работах П.В. Алексеева, посвященных социальной философии, утверждается следующее: экономический детерминизм пережил себя, так как мысль о том, что всякое явление в жизни человеческого общества должно объясняться условиями производства, ошибочна [1]. Экономический детерминизм это крупнейшее направление в социальной философии, и нельзя его отождествлять в целом с марксизмом. Такой характер исследования только осложняет разграничение детерминант и самодетерминант общественной жизни и общественного сознания. Важно со- хранить деление между базисом и надстройкой, общественной жизнью и общественным сознанием, чтобы определить не только их соотношение как факторов общественного развития, но и найти основания для роли человека как подлинной движущей силы истории. П.В. Алексеев соглашается с А.И. Ракитовым в том, что развитие общества во всей эпохе и при всех обстоятельствах в конечном счете определяется способом жизнедеятельности, производством материальных благ, типом культуры, состоянием сознания и самосознания, историческими решениями человека, наконец, типом общественных отношений и взаимодействий [7]. В данном отношении детерминанты и самодетерминанты общественного развития не содержат выделения главного фактора, признается, что верна теория факторов. Однако, современная социальная мысль ушла от подобной позиции, так как для социального самопознания важным является и признание того, что общественное развитие закономерно, но и вместе с тем деятельность людей, через которую осуществляется закономерность, есть форма самодвижения, где проявляется диапазон действий и возникают точки бифуркации. В зависимости от того, какой фактор становится значимым, социальное развитие, социальные изменения не попадают под логику объективных обстоятельств, являются выбором человеком одной из альтернатив общественного развития.

В социально-философском познании действуют три модуса: 1) объективный, который характеризует научную обоснованность выдвинутых положений; 2) субъективный, характеризующий человека как субъекта деятельности; 3) прогностический, связанный со сценарием будущего, логикой общественного развития. Детерминанты и самодетерминанты общественного развития основываются на самопознании, саморефлексии наиболее общих представлений гуманитарного знания. Основной смысл разграничения детерминант и самодетерминант выражается в том, что предлагается системный анализ общественной жизни и общественного развития. В таком контексте детерминанты общественного развития в российском обществе связаны с социально-экономическими трансформациями, изменениями в социальной структуре общества, 
новыми общественными группами и слоями. Очевидно, что известный закон марксизма о соотношении производительных сил и производственных отношений, так же как и схема социально классовой борьбы, не проявляется полно, не может быть монопольной формой социально-философского самопознания.

В российском обществе результатом социальных трансформаций стали размывание социальной структуры, формирование промежуточных нестабильных социальных групп, неопределенность социальных интересов и отсутствие интегрирующих социальных взаимодействий. Детерминанты общественного развития по традиции относятся к сфере социально-экономических отношений. Самодетерминанты определяются как сфера социальной автономности, как логика присоединения или логика эксклюзии по отношению к господствующему классу. Однако, нельзя увлекаться современными зарубежными теориями по той причине, что в них содержится не действующая объяснительно схема самодетерминант (детерминанты игнорируются только как свойственные классической социальной философии).

Выражением этого становится построение множественности социальных теорий, которые связаны с моделированием закономерностей, стремлением соединить социально-философский рефлексивный подход с выработкой ценностных ориентиров, в результате на «выходе» возникает ситуация неопределенности и решения теоретической проблемы в расширении критериев детерминант и самодетерминант общественного развития. В российском обществе неизбежно встает вопрос о том, что социальное развитие должно содержать целью решение социальных противоречий, использование наиболее развитых форм товарной экономики и создание креатосферы (сферы социального творчества, культуры и искусства) как детерминант общественного развития.

Можно возразить по поводу того, что в этом контексте социальная философия превращается в социальное проектирование, и вместе с тем после этих замечаний не следует думать, будто есть необходимость поновому формировать детерминистическую сферу общественного развития. В конечном счете, адекватное понимание детерминант и самодетерминант общественного развития возникает при ситуации социальных альтернатив, когда собственно человек как субъект деятельности становится основным звеном общественного развития.

Данное состояние возникает не вследствие экономического автоматизма, а является преследованием идеальных целей лучшего общественного устройства. Иначе говоря, общество становится сферой самодетерминации по мере того, как ощущается более свободный социальный выбор. Детерминанты общественного развития воспроизводят «вынужденность», зависимость от социальных обстоятельств, но их осознание и понимание необходимо для того, чтобы не переступать пределы социально-разумного, не подвигать общество на недостижимые цели и формировать запрос на сбалансированный социальный выбор.

Самодетерминанты являются отражением гуманистического сдвига в социально-философской мысли, пониманием того, что факты, относящиеся к обществу, и социальные явления вообще следует объяснять исключительно на базе фактов об индивидах, результатах их решений. Вместе с тем не следует удовлетворяться объяснениями в духе методологического индивидуализма, допускать то, что можно смириться с незаконченными или половинчатыми объяснениями масштабных социальных явлений [4].

В социально-философском познании детерминант и самодетерминант общественного развития необходимо руководствоваться широкими социальными перспективами, описывать логику социальных трансформаций и новые реальности общественной жизни и общественного сознания. Нетрудно увидеть, что в российском обществе социальные взаимодействия носят позиционно практический характер, что общественное развитие есть результат зависимости от наличных ситуаций и желаемого образа будущего. В системе методологического индивидуализма эти обобщения не могут быть описаны, так как отрицают коллективного социального субъекта и рассматривают в описании закономерности развития как плохую социальную предопределенность, отнимающую активность индивида. Таким образом, будучи стержнем общественного развития, стимулом струк- 
турных и социально-психологических сдвигов, они образуют мощный контрфактор иррационалистическим тенденциям в общественном сознании [6].

Центральным вопросом социального детерминизма по традиции остается трактовка взаимодействия общества и природы, но такой взгляд слабо выражает специфику социальных процессов, хотя подчеркивает значение деятельности людей, сложность вопроса о социальных детерминантах, воспроизводит представление о законах общества по образцу естественнонаучных законов.

Десциентизация детерминистской теории в социально-философской мысли является сложным процессом, так как может привести к тупикам постмодернизма. Но нет альтернативы сохранению принципа детерминизма в общественном развитии, так как, несмотря на модность теорий типа синергетики, они испытывают взлеты и падения, а изучение детерминант и самодетерминант в общественном развитии российского общества является ответом на запрос, «в каком обществе мы живем и куда мы движемся». Чтобы не удовольствоваться суждением об «ускользающей» социальности, выдвижение на первый план детерминант и самодетерминант общественного развития связано с признанием многомерности общественного взаимодействия и содержит гарантию невозврата к концептам «монофакторности». Современная «индивидная» революция определяет понимание детерминант и самодетерминант общественной жизни в единстве многообразных социальных значений.

Заключение. Подводя итог вышесказанному, следует подчеркнуть, что актуализируемая тема является индикатором новых подходов в социально-философской мысли. Сохраняя традицию детерминизма в рефлексии социальных явлений и процессов, следует принимать во внимание новые социальные реальности (индивидную, информационную, экологическую «революции»). Если социальная философия возвращается к сциентским проекциям, строит схемы детерминизма по аналогии с естественно-научными, результатом является разрыв с процессностью и многомерностью общественной жизни.
Поэтому важным выводом можно считать введение в социально-философский дискурс детерминант и самодетерминант общественной жизни, отмечая, что для социальной философии важна не природная материя, не вещественность, а формы и связи человеческой деятельности, детерминанты общественной жизни определяют совокупность социальных обстоятельств, которые люди в процессе своей деятельности воспринимают как готовые, сложившиеся, имеющие характер стабильных факторов. Под детерминизмом понимают сумму связей, систему отношений, имеющих состояние объективированности, взаимообусловленности с целью зафиксировать определенные закономерности общественной жизни. В традиционной философской мысли детерминанты ассоциировались с экономическими факторами, современное толкование детерминант общественной жизни определяется логикой совместной деятельности людей, включает интеллектуальное, духовное производство. В рамках субъектно-деятельностной концепции значимым становится соотношение детерминант и самодетерминант общественной жизни как связей и отношений, включающих измерение возможностей людей для социальной самореализации на основе субъективного выбора, субъективных самооценок, и, таким образом, можно говорить о «перевертывани» характера зависимости между общественной жизнью и общественным сознанием. Общественная жизнь теряет жесткие границы структурности и приобретает характер субъективно направленного действия. Общественное сознание становится самодетерминантой, движущей силой общественной жизни при условии ее интеллектуализации, онаученности как свидетельства усложнения форм социальной жизни и, с другой стороны, возрастающей способности людей поддержать собственные границы, формируя ответственных за свои действия социальных субъектов, рассматривающих детерминанты и самодетерминанты общественной жизни в качестве различных моделей общественной деятельности.

В российском обществе актуальной является проблема преодоления детерминизма «железных законов истории», и вместе с тем нельзя не признать, что альтернатива в виде методологического индивидуализ- 
ма и запрета на осмысление социальной перспективности на основе детерминант и самодетерминант общественной жизни не может считаться безупречной в контексте запроса российского общества на социальное самосознание.

\section{Литература}

1. Алексеев П.В. Философы России начала XXI столетия: Биографии, идеи, труды. Энциклопедический словарь. - М.: Российская политическая энциклопедия (POCСПЭН), 2009. - 695 с.

2. Балибар Э., Валлерстайн И. Раса, нация, класс. Двусмысленные идентичности [Пер. И. Глущенко и др.]. - М.: Логос-Альтера: Ессе хомо, 2003. - 267 c.

3. Бузгалин A.B. «Постиндустриальное общество» - тупиковая ветвь социального развития? // Экология и жизнь. - 2003. №4. - С. 16-19.

4. Бхаскар Р. Общества // Социо-Логос: Пер. с англ., нем., франц. / Сост., общ. ред. и предисл. В. В. Винокурова, А. Ф. Филиппова. - М.: Прогресс, 1991. - 233 с.

5. Кемеров К. Е., Тиримов К. Х. Хрестоматия по социальной философии. - М.: Академический Проект, 2001. - 571 с.

6. Назаретян А.П. Технология и психология: к концепции эволюционных кризисов// Общественные науки и современность. - 1993. - №3. - С. 82-93.

7. Ракитов А. И. Философия компьютерной революции. - М.: Политиздат, 1991. $287 \mathrm{c}$.

8. Социальная эпистемология: идеи, методы, программы / Под ред. И.Т. Касавина. - М.: «Канон+», РООИ «Реабилитация», 2010. - $712 \mathrm{c}$.

9. Тернер $\Phi$. Европейская интеллектуальная история от Руссо до Ницше / Под ред. Р. Лофтхауса; пер. с англ. Т. О. Новиковой. М.: Кучково поле, 2016. - 384 с.

10. Тощзенко Ж. Т. Парадоксальный человек. - М.: Гардарики, 2001. - 398 с.

\section{References}

1. Alekseev P.V. Filosofy Rossii nachala XXI stoletija: Biografii, idei, trudy. Jenciklopedicheskij slovar' [Philosophers of Russia at the beginning of the XXI century: Biographies, ideas, works. Encyclopedia]. - Moscow: Rossijskaja politicheskaja jenciklopedija (ROSSPJeN), 2009. - 695 p.

2. Balibar Je., Vallerstajn I. Rasa, nacija, klass. Dvusmyslennye identichnosti [Race, nation, class. Ambiguous identities]. - Moscow: Logos-Al'tera: Esse homo, 2003. - 267 p.

3. Buzgalin A.V. «Postindustrial'noe obshhestvo» - tupikovaja vetv' social'nogo razvitija? [«Post-industrial society» - a dead end branch of social development?] // Jekologija i zhizn' [Ecology and life]. — 2003. — №4. - Pp. 16-19.

4. Bhaskar R. Obshhestva [Society] // Socio-Logos / In V.V. Vinokurov, A.F. Filippov (eds.). - Moscow: Progress, 1991. - 233 p.

5. Kemerov K. E., Tirimov K. H. Hrestomatija po social'noj filosofii [Readings in social philosophy]. - Moscow: Akademicheskij Proekt, 2001. - $571 \mathrm{p}$.

6. Nazaretjan A.P. Tehnologija i psihologija: k koncepcii jevoljucionnyh krizisov [Technology and psychology: on the concept of evolutionary crises] // Obshhestvennye nauki i sovremennost' [Social Sciences and modernity]. — 1993. №3. - Pp. 82-93.

7. Rakitov A.I. Filosofija komp'juternoj revoljucii [Philosophy of the computer revolution]. - Moscow: Politizdat, 1991. — 287 p.

8. Social'naja jepistemologija: idei, metody, programmy [Social epistemology: ideas, methods, programs] / In I.T. Kasavin (eds.). Moscow: «Kanon+», ROOI «Reabilitacija», 2010. - 712 p.

9. Terner F. Evropejskaja intellektual'naja istorija ot Russo do Nicshe [European intellectual history from Russo to Nietzsche] / In R. Lofthaus (eds.). Moscow: Kuchkovo pole, 2016. - 384 p.

10. Toshhenko Zh. T. Paradoksal'nyj chelovek [Paradoxical man]. - Moscow: Gardariki, 2001. - 398 p. 


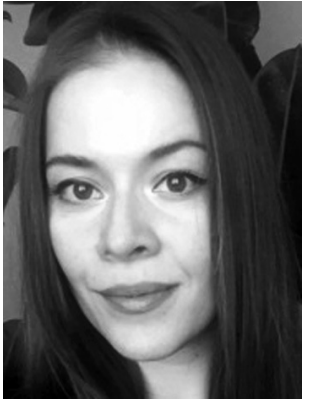

344113, г. Ростов-на-Дону, пр. Космонавтов, 37

37 Kosmonavtov av., 344113, Rostov-on-Don, Russia

E-mail: mkrolman@mail.ru
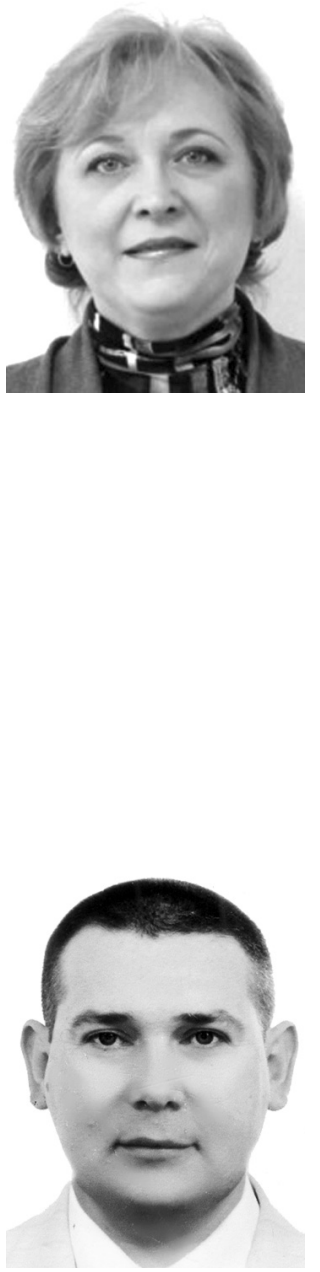

Дементьев Сергей Александрович - кандидат социологических наук, доцент кафедры гуманитарных дисциплин Южно-Российского гуманитарного института.

Dementiev Sergey Alexandrovich - Candidate of Sociological Sciences, Associate Professor of the Department of Humanities, South Russian Humanitarian Institute.

344015 , г. Ростов-на-Дону, ул. Еременко, 83

83 Eremenko st., 344015, Rostov-on-Don, Russia

E-mail: kosarevaelena@mail.ru

344082, г. Ростов-на-Дону, ул. Красноармейская, 108

108 Krasnoarmeyskaya st., 344082, Rostov-on-Don, Russia

E-mail: s.a.dementiev2014@yandex.ru 